\title{
Distribution of Substance $P$ and Methionine-Enkephalin in Salivary Glands and Effect of Chronic Morphine Treatment on Levels of These Peptides
}

\author{
Norifumi YONEHARA, Huei-Yann TSAI, Ji-Qiang CHEN \\ and Reizo INOKI \\ Department of Pharmacology. Faculty of Dentistry. Osaka University. \\ Suita, Osaka 565, Japan \\ Accepted May 24, 1989
}

\begin{abstract}
Substance P-like immunoreactivity (SPLI) and methionine-enkephalinlike immunoreactivity (MELI) were determined in salivary glands from rats by radioimmunoassay. In all salivary glands investigated (submandibular gland. sublingual gland and parotid gland), SPLI and MELI were detected. The amount of both peptides is comparable to or relatively higher than those found in any other peripheral tissue. The level of SPLI showed a tendency to increase following chronic treatment with morphine: the enhancement in the submandibular gland and the sublingual gland was especially remarkable. The level of MELI was decreased, particularly in the submandibular gland.
\end{abstract}

The undecapeptide substance $P$ (SP) was originally identified in the extract from horse intestine (1) and was subsequently isolated from the bovine hypothalamus, sequenced and synthesized (2, 3). This made it possible to develop highly specific immunohistochemical and radioimmunological techniques for detailed mapping of the distribution and release of SP. These studies have demonstrated that SP is widely located in the periphery such as the salivary glands, tongue. tooth pulp and most visceral tissue, as well as the central nervous system. In the salivary glands of the rat, the concentration of SP-like immunoreactivity (SPLI) is high (4, 5); and furthermore, SP containing nerves have been demonstrated by immunohistochemical studies (6). In addition, it was shown that SP caused a pronounced sialogogic action (7). and SP-induced salivary secretion was modulated by peptides such as vasopressin, angiotensin and neurotensin (8). Recent histological and physiological studies on neuropeptides have suggested that the physiological function of SP might be linked with opioid peptides. For example, it has been shown that the stimulus-evoked SP release from the small-diameter afferent fibers is inhibited by opioids (9). Kudo et al. have shown that the distribution of opioid peptide immunoreactive fibers showing varicose fluorescent fibers is similar to that of SPLI-fibers in salivary glands (10). These findings suggested that there may be some interaction between SP and opioid systems in salivary glands. Therefore, we have measured methionine-enkephalin-like immunoreactivity (MELI) and SPLI and we examined the influence of chronic morphine treatment on the level of these peptides.

Male Sprague-Dawley rats weighing 150$200 \mathrm{~g}$ were killed by decapitation: and the submandibular gland, the sublingual gland and the parotid gland were immediately removed. Each of the salivary glands was separately rinsed in ice-cold saline and then homogenized with $2 \mathrm{ml}$ of ice-cold $0.1 \mathrm{~N}$ $\mathrm{HCl}$ using a Polytron homogenizer. After centrifugation at $100.000 \times \mathrm{g}$ for $30 \mathrm{~min}$, the supernatant was lyophilized and then stored at $-80^{\circ} \mathrm{C}$ until analyzed. The methods of SP and [Met ${ }^{5}$ ]enkephalin radioimmunoassays have been described previously (9). In the SP and $\left[\mathrm{Met}^{5}\right]$ enkephalin radio- 
immunoassays, we used antiserums raised in rabbits against bovine thyroglobulinconjugated synthetic SP and [Met $\left.{ }^{5}\right]$ enkephalin, respectively. The antiserum of SP showed less than 1 and $0.2 \%$ crossreactivity with neurokinin $A$ and neurokinin $B$, respectively, and no cross-reactivity with opioids such as $\left[\mathrm{Met}^{5}\right]$ enkephalin, [Leu ${ }^{5}$ ]enkephalin and morphine. The antiserum of [Met ${ }^{5}$ enkephalin showed less than $0.4 \%$ crossreactivity with [Leu ${ }^{5}$ ]enkephalin and no cross-reactivity with $S P$ and morphine. To render rats morphine-tolerant/dependent. morphine was injected intraperitoneally with a dose of $6 \mathrm{mg} / \mathrm{kg}$. twice a day, for 7 days; and the rats were sacrificed twelve hours after the last injection. As a control, some rats were administered saline on the same schedule as morphine treatment.

As shown in Table 1, appreciable amounts of SPLI and MELI were detected in the salivary glands. There was no significant variation in the SPLI levels measured among the submandibular gland, sublingual gland and parotid gland, while the distribution of MELI was quite different from that of SPLI. MELI in the submandibular gland was about ten times higher than the level of SPLI, and MELI in the other two glands was about one sixth of SPLI. The level of SPLI in chronic morphine-treated rats showed a tendency to increase; particularly, the enhancement in the submandibular gland and sublingual gland was significant (Fig. 1A). In the same experiments, the level of MELI was also assayed in parallel. The level of MEL! was decreased. and in the submandibular gland, it was significant (Fig. 1B).

In the present experiments, all extracts from the salivary glands investigated showed high levels of SPLI and MELI compared with other organs. The levels of the peptides observed in the salivary glands are in the same range as or higher than those in the gastrointestinal tract, which is considered as a tissue containing appreciable amounts of neuropeptides such as SP and enkephalins. In this connection. Brodin and Nilsson have shown that the salivary glands contain the highest SPLI of all organs analyzed in the rat (5). There was no difference in SPLI levels among the three salivary glands investigated. while the distribution of MELI was quite different from that of SPLI, as shown in Table 1. There is no evidence explaining why such marked variety of MELI exists among these salivary glands. However, it is important to know that MELI could be detected in all the salivary glands, since the interaction between SP and enkephalin was recently indicated by direct or indirect evidences that opioids could inhibit the release of SP from peripheral nervous tissues (11) and primary sensory neurons (9). To look at the possibility of a functional interaction between $S P$ and methionine-enkephalin, we measured $S P L I$ and MELI levels in salivary glands following chronic morphine treatment. As shown in Fig. 1. our observation of an increase in the levels of SPLI and a decrease in the levels of MELI after chronic morphine treatment was similar to the previous findings in the central nervous system (12-14). The opposite effect of chronic morphine treatment on SPLI and MELI levels indicates that enkephalin and SPLI systems existing in salivary glands may interact as demonstrated in areas of the central nervous system related to pain pathways. In this connection, morphine has been reported to inhibit the salivary flow induced by electrical stimulation of the chorda tympani whose section resulted in decrease of the SP content of salivary glands $(4,15)$

At present. further experiments are needed to explain the marked variety of MELI among

Table 1. Tissue concentration of SPLI and MELI in salivary glands of the rat

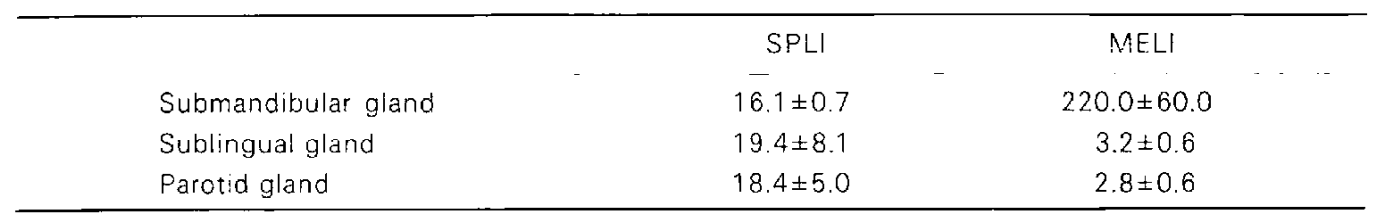

Value is expressed as pmol/g tissue wet weight and the mean \pm S.E.M. of at least 5 experiments. 

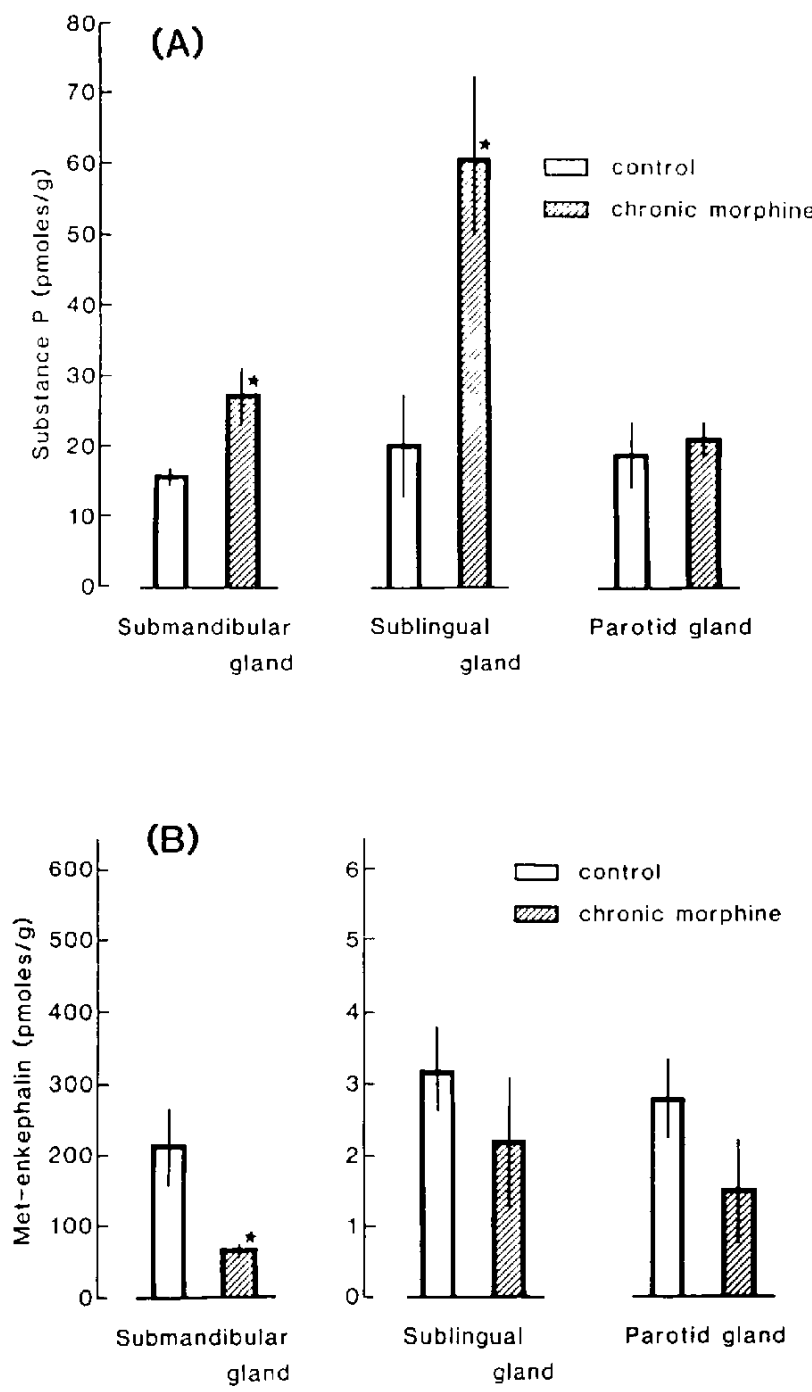

Fig. 1. Effect of chronic morphine treatment on the tissue concentration of $S P L /(A)$ and $M E L I(B)$ in salivary glands of the rat. Columns represent the mean \pm S.E.M. of at least 5 experiments. $\star P<0.05$. significantly different from the control.

salivary glands and the difference of range of alteration in SPLI and MELI levels by chronic morphine treatment among the salivary glands.

Acknowledgment: We thank Dr. D.H. Clouet (NIH) for comments on the manuscript. This work was partly supported by a Grant-in-Aid for Scientific Research from the Ministry of Education. Science and Culture of Japan.

\section{References}

1 Von Euler, U.S. and Gaddum, J.H.: An un- identified depressor substance in certain tissue extracts. J. Physiol. (Lond.) 72, 74-87 (1931)

2 Chang, M.M. and Leeman, S.E.: Isolation of sialogogic peptide from bovine hypothalamic tissue and its characterization as substance $P$. J. Biol. Chem, 245, 4784-4790 (1970)

3 Chang, M.M., Leeman, S.E. and Niall, H.D.: Amino acid sequence of substance $P$. Nature; New Biol, 232, 86-87 (1971)

4 Robinson, S.E., Schwartz, J.P. and Costa, E.: Substance $P$ in the superior cervical ganglion and the submaxillary gland of the rat. Brain Res. $182,11-17$ (1980) 
5 Brodin, E. and Nilsson, G.: Concentration of substance P-like immunoreactivity (SPLI) in tissues of the dog, rat and mouse. Acta Physiol. Scand. 112, 305-312 (1981)

6 Hökfelt, T., Johansson, O., Kellerth, J.-O., Ljungdahl, A., Nilsson, G., Nygards, A. and Pernow, B.: immunohistochemical distribution of substance $P$. In Substance P. Nobel Symposium 37. Edited by Von Euler. U.S. and Pernow. B., p. 117-145. Raven Press, New York (1977)

7 Vogler, K., Haefely, W., Hurlimann, A., Studer, R.O., Lergier, W., Strassle, R. and Berneis, K.H.: A new purification procedure and biological properties of substance P. Ann. N.Y. Acad. Sci. 104, 378-389 (1963)

8 Liang, T. and Cascieri, M.A.: Substance P stimu. lation of amylase release by isolated parotid cells and inhibition of substance $P$ induction of salivation by vasoactive peptides. Mol. Cell. Endocrinol. 15, 151-162 (1979)

9 Yonehara, N., Shibutani, T., Tsai, H.-Y. and Inoki, R.: Effects of opioids and opioid peptide on the release of substance $P$-like material induced by tooth pulp stimulation in the trigeminal nucleus caudalis of the rabbit. Eur. J. Pharrnacol. 129, 209-216 (1986)

10 Kudo, T., Inoki, R., Nishimoto, T., Akai, M.,
Shiosaka, S. and Toyama, M.: A possible role of substance $P$ in the salivary secretion in rats. Adv. Exp. Med. Biol. 156A, 681-692 (1983)

11 Brodin, E., Gazelius, B., Panapoulos, P. and Olgart, L.: Morphine inhibits substance $P$ release from peripheral sensory nerve endings. Acta Physiol. Scand. 177, 567-570 (1983)

12 Naftchi, N.E., Abrahams, S.J., St. Paul, H.M. and Vacca, L.L.: Substance $P$ and leucineenkephalin changes after chordotomy and morphine treatment. Peptides 2, 61-70 (1981)

13 Clowet, D.H. and Ratner, M.: The incorporation of ${ }^{3} \mathrm{H}$-glycine into enkephalins in the brains of morphine treated rats. In Opiates and Endogenous Opioid Peptides, Edited by Kosterlitz, H.W., p. 71-78, Elsevier/North-Holland Biomedical Press, Amsterdam (1976)

14 Bergstrom, L., Sakurada, T, and Terenius, L.: Substance $P$ leveis in various regions of the rat central nervous system after acute and chronic morphine treatment. Life Sci. 35, 2375-2382 (1984)

15 Corrado, A.P. and Grellet, M.: Mechanism of the sialagogic effect induced by bradykinin in dogs: possible mediation by endogenous prostaglandin. Adv. Exp. Med. Biol. 70, 81-95 (1976) 